\title{
Sequence and Relationships of Sugarcane Mosaic and Sorghum Mosaic Virus Strains and Development of RT-PCR-Based RFLPs for Strain Discrimination
}

\author{
Z. N. Yang and T. E. Mirkov
}

Department of Plant Pathology and Microbiology, Texas Agricultural Experiment Station, Texas A\&M University System, 2415 E. Highway 83, Weslaco 78596.

Accepted for publication 12 May 1997.

\begin{abstract}
Yang, Z. N., and Mirkov, T. E. 1997. Sequence and relationships of sugarcane mosaic and sorghum mosaic virus strains and development of RTPCR-based RFLPs for strain discrimination. Phytopathology 87:932-939.

Sugarcane mosaic is the most widespread virus disease affecting sugarcane production. We have established a collection of seven prominent sugarcane mosaic potyvirus (SCMV) strains currently causing disease in sugarcane throughout the world and originally found in sugarcane in the United States. This collection includes SCMV strains A, B, D, and E, and the sorghum mosaic virus (SrMV) strains SCH, SCI, and SCM. These viruses were propagated on Sorghum bicolor cv. Rio and purified. Cloned cDNAs representing $2.0 \mathrm{~kb}$ of the $3^{\prime}$ termini, obtained after a reversetranscriptase-polymerase chain reaction (RT-PCR) on purified virions

using an oligo(dT) primer and degenerate primers with sequences located in the NIb gene, have been sequenced for each of these strains. A comparative analysis of the deduced amino acid sequences in the $\mathrm{NIb}$ and coat protein genes and of the nucleotide sequences in the $3^{\prime}$-untranslated region, among these seven viruses and among six other members of the SCMV subgroup, confirms that there are at least four, but suggests that there are five, distinct viruses in the SCMV complex. Based on these seven new sequences and on the available sequence data for six other members of the SCMV subgroup, we have developed group-specific primers for use in RT-PCR-based restriction fragment length polymorphism analysis for rapid discrimination between strains of SCMV and SrMV. This is the first assay for differentiating strains of SCMV and SrMV that does not require interpretation of symptoms on differential hosts.
\end{abstract}

The potyvirus group is the largest and, possibly, economically most important group of the plant viruses, and sugarcane mosaic virus (SCMV) is a definitive member of this group $(10,13,20)$. SCMV occurs in many parts of the world where susceptible species are grown and it causes mosaic disease and yield loss in sugarcane, maize, sorghum, and other poaceous plants. The SCMV complex has been shown to consist of four distinct potyviruses (18) and includes strains of Johnsongrass mosaic virus (JGMV), maize dwarf mosaic virus (MDMV), sorghum mosaic virus (SrMV), and SCMV. In sugarcane, strains of SCMV and SrMV are the most widespread viruses of this crop, and they can reduce sugar yields significantly. In the mid-1920s, disease epidemics caused by members of the SCMV subgroup accounted for a near collapse of the industry in Argentina, Brazil, and Louisiana. Although these epidemics were brought under control with the introduction of resistant sugarcane cultivars, strains of SCMV and SrMV continue to be a potential threat to the industry (7).

In the United States, 21 potyviruses belonging to the SCMV subgroup have been reported (16), and, of these, five strains of SCMV and three strains of SrMV are currently present in sugarcane fields throughout the world (7). Historically, isolates first found in sugarcane were designated as strains of SCMV (1) and those found in maize as strains of MDMV (9). However, strains of SCMV and MDMV were found to share many common properties and, therefore, MDMV was considered to be a strain of SCMV (13). Recent taxonomic research $(8,11,16)$ on a large number of strains of viruses in the SCMV complex, based on biochemical properties of coat proteins, led to the conclusion that the complex is actually

Corresponding author: T. E. Mirkov; E-mail address: e.mirkov@tamu.edu

Publication no. P-1997-0613-01R

(C) 1997 The American Phytopathological Society comprised of four distinct potyviruses, and the addition of the SrMV and JGMV nomenclature and grouping has been adopted $(16,18)$. To date, however, the various biochemical and serological techniques used for taxonomic separation cannot distinguish the strains of SCMV and SrMV (16) and, therefore, host reaction remains the only method to distinguish individual strains (6).

To investigate these relationships at the molecular level, develop a rapid, nucleic acid-based method for strain discrimination, and assist us in our design of coat protein constructs to be used in a transgenic approach for control of these viruses, we have established a collection of the prominent SCMV and SrMV strains currently causing disease in sugarcane throughout the world and originally found in sugarcane in the United States. This includes SCMV strains A, B, D, and E, and the SrMV strains SCH, SCI, and SCM. In this study, cloned cDNAs representing about $2.0 \mathrm{~kb}$ of the $3^{\prime}$ termini, obtained after reverse-transcriptase-polymerase chain reaction (RT-PCR) on purified virions using an oligo(dT) primer and degenerate primers with sequences located in the NIb gene, have been sequenced for each of these strains.

\section{MATERIAL AND METHODS}

Virus isolates and purification. The SCMV strains used in this study were SCMV-A, SCMV-B, SCMV-D, SCMV-E, SrMVSCH, SrMV-SCI, and SrMV-SCM. The SCMV strains A, B, and $\mathrm{D}$, and the SrMV strains SCI and SCM were obtained from the culture collection maintained by M. Grisham (USDA Sugarcane Research Unit, Houma, LA). The SCMV-E isolate was obtained from M. Irey (US Sugar Corporation, Clewiston, FL). The SrMV$\mathrm{SCH}$ isolate was isolated from a field plot of $\mathrm{NCo}-310$ grown in southern Texas and will be referred to as SrMV-SCH (TX). Total RNA purified (as described below) from plants infected with unknown field isolates collected in Florida and Africa was provided 
by P. Rott (CIRAD, Montpellier, France). All strains were inoculated on Sorghum bicolor cv. Rio, and virions were purified as described previously (22).

Cloning and sequencing strategy. To obtain cDNAs that represented about $2.0 \mathrm{~kb}$ of the 3 '-terminal end of the genome for each of the seven strains, we utilized a one-tube RT-PCR strategy that was performed directly on purified virions. The design of the forward primers was based on amino acid motifs in the carboxyterminal region of the NIb gene that are highly conserved among potyviruses (3) (Table 1). One to $10 \mu \mathrm{g}$ of purified virions, $0.5 \mu \mathrm{g}$ of the forward primer, and $0.5 \mu \mathrm{g}$ of the reverse primer, oligo $(\mathrm{dT})_{24} \mathrm{~N}$, in a $20-\mu \mathrm{l}$ final volume were incubated at $55^{\circ} \mathrm{C}$ for $5 \mathrm{~min}$. Virions and primers were then added to a RT-PCR reaction mix $(100-\mu 1$ final volume) that consisted of $20 \mathrm{mM}$ Tris, pH $9.0,50 \mathrm{mM} \mathrm{KCl}$, $2.5 \mathrm{mM} \mathrm{MgCl} 2,0.1 \%$ Triton X-100, $10 \mathrm{mM}$ dithiothreitol (DTT), $0.2 \mathrm{mM}$ each deoxynucleoside triphosphate (dNTP), 20 units of RNasin (Promega Corp., Madison, WI), 15 units of avian myeloblastosis virus reverse transcriptase (Promega Corp.), and 2.5 units of AmpliTaq DNA polymerase (Perkin-Elmer Corp., Norwalk, CT). Reverse transcription and PCR were performed in a PerkinElmer Cetus 480 thermal cycler (Perkin-Elmer Cetus, Norwalk, CT) programmed to give one cycle at $42^{\circ} \mathrm{C}(60 \mathrm{~min})$; two cycles at $94^{\circ} \mathrm{C}(5 \mathrm{~min}), 37^{\circ} \mathrm{C}(3 \mathrm{~min})$, and $72^{\circ} \mathrm{C}(3 \mathrm{~min}) ; 35$ cycles at $94^{\circ} \mathrm{C}(1 \mathrm{~min}), 52^{\circ} \mathrm{C}(1 \mathrm{~min})$, and $72^{\circ} \mathrm{C}(1$ to $3 \mathrm{~min})$; and a final cycle at $72^{\circ} \mathrm{C}(7 \mathrm{~min})$. A $10-\mu \mathrm{l}$ aliquot of the RT-PCR products was analyzed by electrophoresis in a $1 \%$ agarose gel (15). Reaction products of the expected sizes were excised from the gel and eluted using a GENECLEAN II Kit (BIO 101 Inc., La Jolla, CA), and the DNA fragments were cloned directly into pCRII (Invitrogen Corp., San Diego, CA). Recombinant plasmids were analyzed for appropriate size inserts by cleavage with EcoRI. For sequencing, plasmids with inserts of the expected size were amplified in Escherichia coli and purified using a Qiagen plasmid purification kit (Qiagen, Inc., Chatsworth, CA).

The cDNAs were sequenced by the Sequenase 2.0 dideoxy chain termination method (United States Biochemical Corp., Cleveland) as detailed by the manufacturer using external $\mathrm{T} 7$ and SP6 primers, or internal oligonucleotides based on the previously determined sequence. Both strands of at least two independent clones were sequenced (Fig. 1). A third clone was sequenced when there was a disagreement between the sequences of the first two clones (Table 2). Nucleotide and amino acid sequences were analyzed with the Genetics Computer Group (GCG) sequence analysis software from the University of Wisconsin (4) and Clustal W (21). Phylogenetic trees were constructed by the neighbor-joining method, and the statistical significance of branch order was estimated by 1,000 replications of bootstrap resampling of the original align-

TABLE 1. Primers used for cloning and reverse-transcriptase-polymerase chain reaction (RT-PCR) analysis

\begin{tabular}{ll}
\hline Primer designation & \multicolumn{1}{c}{ Sequence $^{\mathrm{a}}$} \\
\hline $\begin{array}{l}\text { Cloning primers } \\
\text { Forward primers } \\
\text { pot2 }\end{array}$ & \\
sc1 & TGYGAYGCNGATGGYTC \\
sc5 & CHATWTTGGARTGGGAYG \\
Reverse primers & TGYGATGCMGATGGTTCRCAA \\
sc2 & \\
sc3 & ATTCCACCATTGCAGCAC \\
sc4 & ATGGGAAGACTGTTTGTT \\
(dT) & CTCTGTCGAGTTCCGATACTC \\
Primers for RT-PCR restriction fragment length polymorphism analysis \\
SCMV F3 & TTTYCACCAAGCTGGAA \\
SCMV R3 & AGCTGTGTGTCTCTCTGTATTCTC \\
SrMV F3 & AAGCAACAGCACAAGCAC \\
SrMV R3 & TGACTCTCACCGACATTCC \\
\hline
\end{tabular}

${ }^{a}$ Redundancy code: $\mathrm{N}=\mathrm{A}+\mathrm{C}+\mathrm{T}+\mathrm{G}, \mathrm{M}=\mathrm{A}+\mathrm{C}, \mathrm{R}=\mathrm{A}+\mathrm{G}, \mathrm{Y}=\mathrm{C}+\mathrm{T}$, $\mathrm{W}=\mathrm{A}+\mathrm{T}$, and $\mathrm{H}=\mathrm{T}+\mathrm{C}+\mathrm{A}$. ments by Clustal W (21). The Clustal W parameter that allows alignment positions where any of the sequences have a gap to be ignored was used for construction of the trees.

Diagnostic restriction fragment length polymorphisms (RFLPs). Based on multiple sequence alignments of our new sequences and published sequences for six other members of the SCMV subgroup, two group-specific primer pairs were designed: primer pair SCMV F3 and R3 for SCMV strains, and primer pair SrMV F3 and R3 for SrMV strains (Table 1). Total RNA was extracted and purified from $150 \mathrm{mg}$ of systemically infected sorghum or sugarcane leaves using Plant RNeasy Total RNA columns (Qiagen, Inc.) and eluted in a final volume of $50 \mu \mathrm{l}$ of diethylpyrocarbonate-treated water. Four microliters of the eluted RNA, $3 \mu \mathrm{l}$ of a $2.5 \mathrm{mM}$ dNTP mix, $3 \mu \mathrm{l}$ of $5 \times$ first-strand buffer $(250 \mathrm{mM}$ Tris- $\mathrm{HCl}$ [pH 8.3], $375 \mathrm{mM} \mathrm{KCl}$, and $15 \mathrm{mM} \mathrm{MgCl}_{2}$ ), $1 \mu \mathrm{g}$ of random primers (random hexadeoxyribonucleotides; Promega Corp.), and $2 \mu \mathrm{l}$ of $\mathrm{H}_{2} \mathrm{O}$ were incubated at $65^{\circ} \mathrm{C}$ for $3 \mathrm{~min}$, and then transferred to ice for $3 \mathrm{~min}$. For the reverse transcription step, $0.5 \mu \mathrm{l}$ of 100 mM DTT, 40 units of RNasin (Promega Corp.), and 200 units

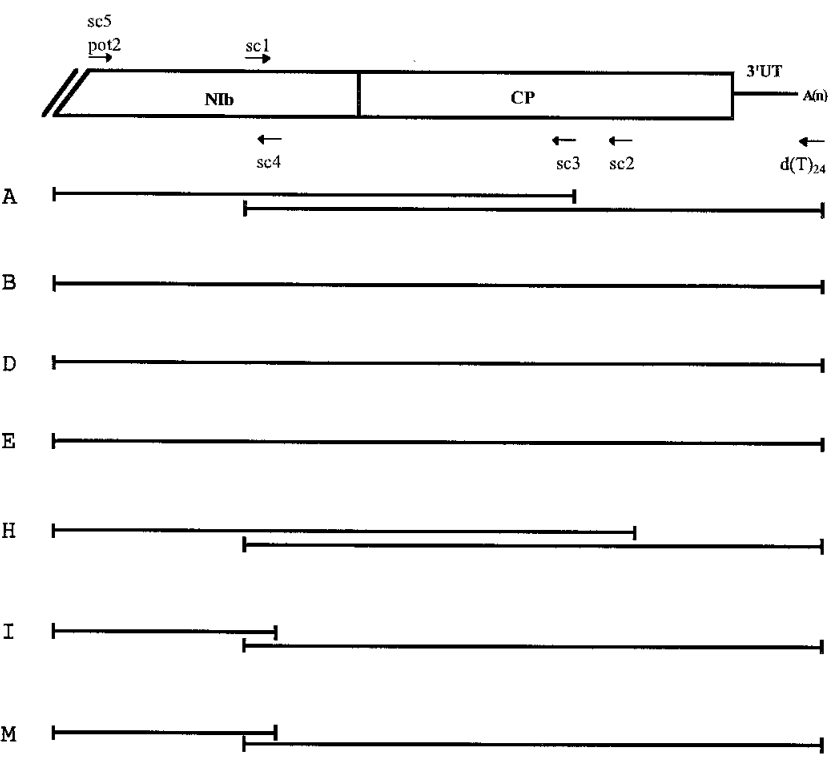

Fig. 1. Schematic representation of the 3'-terminal region of the sugarcane mosaic potyvirus genome and the cloning strategy used in this work. Genes are presented as rectangles. $\mathrm{NIb}=$ putative RNA-dependent RNA polymerase, $\mathrm{CP}=$ coat protein, and $3^{\prime} \mathrm{UTR}=3^{\prime}$-untranslated region. Arrows represent position of cloning primers with the corresponding primer designation (Table 1). Horizontal bars represent clones used for sequencing, with the respective strains indicated to the left.

TABLE 2. Nucleotide differences between two independent clones that result in amino acid changes

\begin{tabular}{lcccc}
\hline Strain & $\begin{array}{c}\text { Nucleotide } \\
\text { position }\end{array}$ & Region $^{\mathrm{b}}$ & $\begin{array}{c}\text { Nucleotide } \\
\text { difference }\end{array}$ & $\begin{array}{c}\text { Amino acid } \\
\text { change }\end{array}$ \\
\hline SCMV-A & 749,750 & NIb & GT-AA & Gly-Glu \\
SCMV-B & 905 & CP & T-C & Val-Ala \\
& 991 & CP & A-G & Ser-Gly \\
& 1,340 & CP & A-G & Glu-Gly \\
& 1,465 & CP & G-A & Glu-Lys \\
& 1,487 & CP & G-A & Arg-Gln \\
SCMV-E & 1,619 & CP & T-C & Val-Ala \\
SrMV-SCI & 1,036 & CP & A-G & Ile-Val \\
& 884 & CP & C-T & Ala-Val \\
& 898 & CP & A-G & Thr-Ala \\
SrMV-SCM & 1,148 & CP & G-A & Arg-Lys \\
\hline
\end{tabular}

a Numbering begins with the 5 '-terminal nucleotide of the clones generated in this work as indicated in Figure 1.

${ }^{\mathrm{b}} \mathrm{CP}=$ coat protein. 
of SuperScript II reverse transcriptase (Gibco BRL, Gaithersburg, MD) were added to the above mixture and incubated at $37^{\circ} \mathrm{C}$ for $60 \mathrm{~min}$. Two microliters of the reverse transcription products was used as a template for PCR. The PCR reaction mix (100- $\mu$ l final volume) consisted of $250 \mathrm{ng}$ of each primer, $60 \mathrm{mM}$ Tris- $\mathrm{HCl}(\mathrm{pH}$ 8.5), $75 \mathrm{mM}\left(\mathrm{NH}_{4}\right)_{2} \mathrm{SO}_{4}$, and $2 \mathrm{mM} \mathrm{MgCl}$. The cycling parameters were one cycle at $94^{\circ} \mathrm{C}(2 \mathrm{~min}) ; 40$ cycles at $94^{\circ} \mathrm{C}(1 \mathrm{~min})$, $60^{\circ} \mathrm{C}(1 \mathrm{~min})$, and $72^{\circ} \mathrm{C}(1 \mathrm{~min})$; and a final cycle at $72^{\circ} \mathrm{C}$ for 7 min. The amplified products were precipitated from the aqueous phase by addition of sodium acetate to $0.3 \mathrm{M}$ and 2.5 volumes of ethanol. The pellets were washed with $70 \%$ ethanol two times and dissolved in $20 \mu \mathrm{l}$ of distilled water. The PCR products generated from SCMV strains were digested with TaqI, or HinfI, or ApoI and XbaI. The PCR products generated from SrMV strains were

TABLE 3. Percent amino acid sequence identity between the coat protein genes and NIb genes from strains of viruses in the sugarcane mosaic virus (SCMV) subgroup $^{\mathrm{a}, \mathrm{b}}$

\begin{tabular}{|c|c|c|c|c|c|c|c|c|c|c|c|c|c|c|}
\hline & $\begin{array}{l}\text { JGMV- } \\
\text { MDKS1 }\end{array}$ & $\begin{array}{l}\text { JGMV- } \\
\text { MDO }\end{array}$ & $\begin{array}{l}\text { JGMV- } \\
\text { JG }\end{array}$ & $\begin{array}{c}\text { SCMV- } \\
\text { A }\end{array}$ & $\begin{array}{c}\text { SCMV- } \\
\text { E }\end{array}$ & $\begin{array}{c}\text { SCMV- } \\
\text { B }\end{array}$ & $\begin{array}{l}\text { SCMV- } \\
\text { D }\end{array}$ & $\begin{array}{c}\text { SCMV- } \\
\text { SC }\end{array}$ & $\begin{array}{l}\text { SCMV- } \\
\text { MDB }\end{array}$ & $\begin{array}{l}\text { SrMV- } \\
\text { SCI }\end{array}$ & $\begin{array}{l}\text { SrMV- } \\
\text { SCM }\end{array}$ & $\begin{array}{l}\text { SrMV-SCH } \\
\text { (TX) }\end{array}$ & $\begin{array}{l}\text { SrMV- } \\
\text { SCH }\end{array}$ & $\begin{array}{c}\text { MDM } \\
\text { V-A }\end{array}$ \\
\hline JGMV-MDKS1 & & 99 & 94 & 59 & 60 & 58 & 59 & 59 & 59 & 56 & 57 & 57 & 56 & 59 \\
\hline JGMV-MDO & 100 & & 93 & 59 & 60 & 58 & 59 & 59 & 59 & 56 & 57 & 57 & 56 & 59 \\
\hline SCMV-A & 31 & 16 & 50 & & 97 & 98 & 99 & 97 & 86 & 75 & 75 & 75 & 74 & 77 \\
\hline SCMV-E & 33 & 22 & 50 & 97 & & 95 & 96 & 95 & 83 & 75 & 75 & 75 & 73 & 76 \\
\hline SCMV-B & 33 & 22 & 50 & 99 & 98 & & 98 & 96 & 84 & 75 & 75 & 75 & 73 & 76 \\
\hline SCMV-D & 33 & 22 & 50 & 98 & 98 & 100 & & 97 & 84 & 75 & 75 & 76 & 73 & 76 \\
\hline SrMV-SCI & 36 & 28 & 54 & 77 & 76 & 77 & 77 & 69 & 73 & & 99 & 98 & 96 & 80 \\
\hline SrMV-SCM & 36 & 28 & 53 & 77 & 76 & 77 & 77 & 69 & 73 & 100 & & 98 & 96 & 80 \\
\hline SrMV-SCH (TX) & 36 & 28 & 53 & 76 & 75 & 76 & 76 & 67 & 71 & 99 & 99 & & 97 & 80 \\
\hline SrMV-SCH & 36 & 28 & 53 & 77 & 76 & 77 & 76 & 69 & 73 & 99 & 99 & 98 & & 79 \\
\hline MDMV-A & 28 & 19 & 47 & 75 & 75 & 75 & 75 & 58 & 58 & 80 & 79 & 79 & 79 & \\
\hline
\end{tabular}

a The sources of sequence data were GenBank accession numbers D00094 (JGMV-JG), U07217 (JGMV-MDO), U07218 (JGMV-MDKS1), D00948 (SCMVSC), U07216 (MDMV-A), D00947 (SCMV-MDB), and U07219 (SrMV-SCH). The sequences determined in this study are GenBank accession numbers U57354 (SCMV-A), U57355 (SCMV-B), U57356 (SCMV-D), U57357 (SCMV-E), U57358 (SrMV-SCH TX), U57359 (SrMV-SCI), and U57360 (SrMVSCM). Sequence identities were calculated by making pairwise comparisons using the Gap program (University of Wisconsin Genetics Computer Group, Madison). ${ }^{\mathrm{b}}$ Comparisons above the diagonal refer to the coat protein genes and comparisons below the diagonal refer to partial sequences of the NIb genes.

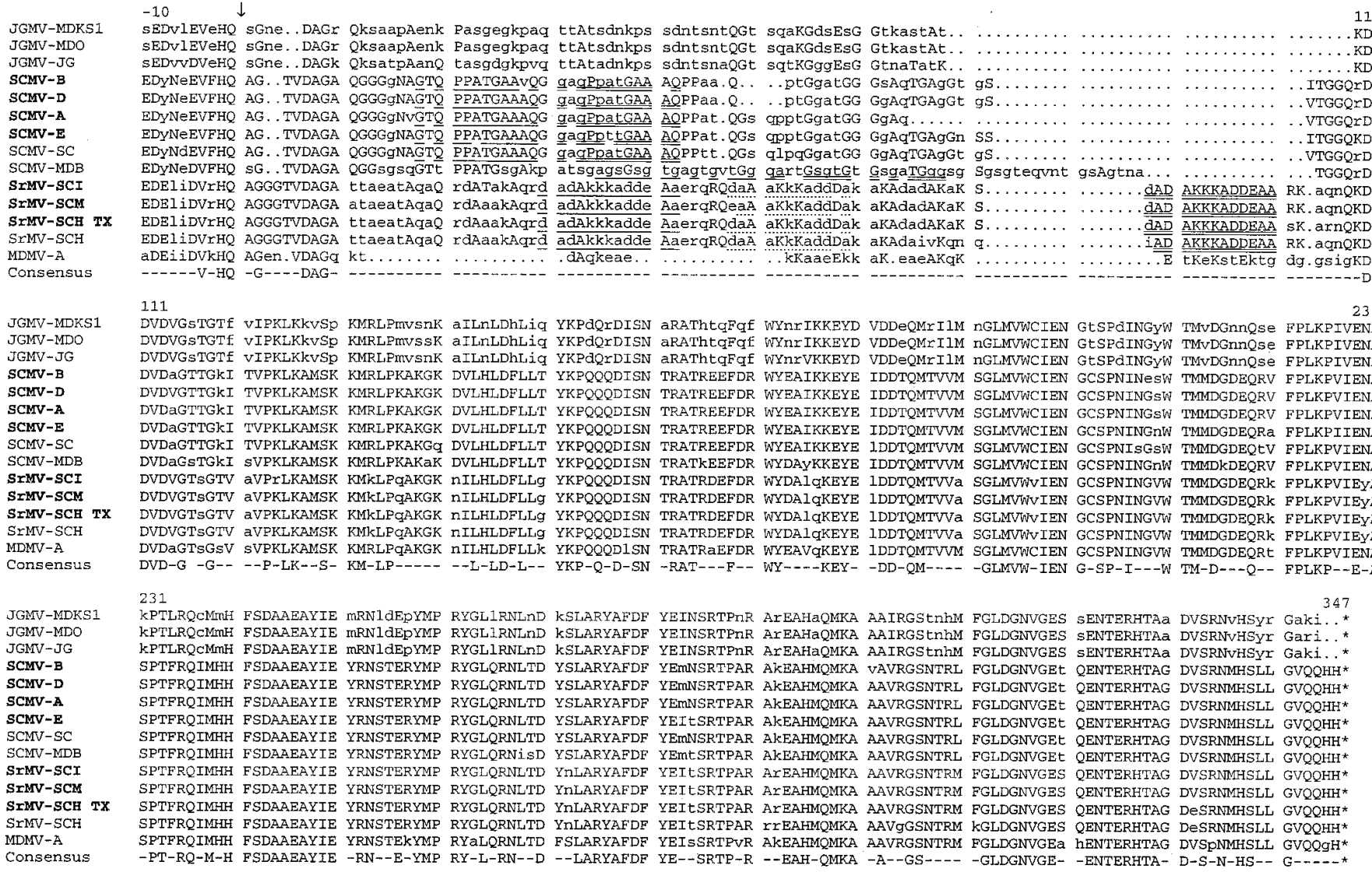

Fig. 2. Multiple alignment of deduced amino acid sequences of coat protein genes from 13 members in the sugarcane mosaic potyvirus subgroup. The alignment was generated using the PileUp and Pretty programs (University of Wisconsin Genetics Computer Group, Madison). Seven of these sequences have already been published; sequences of new strains are indicated in bold. The arrow indicates the putative cleavage site between the NIb gene product and coat protein. Duplicated peptide sequences are underlined. Consensus amino acids are given as upper case, and the Consensus line shows only amino acids that are identical for all 14 members. 
digested with $H g a \mathrm{I}$ or TaqI and Sau3AI. The digestion products were analyzed by electrophoresis through a $1.7 \%$ agarose gel or a $6 \%$ polyacrylamide gel (14).

\section{RESULTS}

Cloning and sequencing strategy. Clones representing approximately $2.0 \mathrm{~kb}$ of the $3^{\prime}$-terminal region of the viral genome were obtained in one step for the SCMV strains B, D, and E. This was achieved using the forward primer pot 2 and an oligo(dT) primer as the reverse primer (Table 1, Fig. 1). The pot2 primer is a degenerate primer coding for the amino acid sequence CDADGS, which is a highly conserved motif in the NIb genes of potyviruses (3). For strains SCMV-A, SrMV-SCH, SrMV-SCI, and SrMV$\mathrm{SCM}$, clones representing approximately $2.0 \mathrm{~kb}$ of the 3 '-terminal region of the viral genome were obtained in two steps. First, primer sc1 and an oligo(dT) primer (Table 1, Fig. 1) were used to amplify the $3^{\prime}$ end of the NIb gene, the coat protein gene, and the 3 '-untranslated region. The degenerate sc1 primer was based on a conserved amino acid motif (SILEWDR) identified in the NIb genes of strains B, D, and E. In the second step, the upstream region of the NIb gene corresponding to that obtained for strains B, $\mathrm{D}$, and $\mathrm{E}$ was amplified with reverse primers based on previously determined sequences in the coat protein $(\mathrm{sc} 2$ or $\mathrm{sc} 3)$ or NIb genes (sc4), and forward primers pot2 or sc5 (Table 1, Fig. 1). The degenerate primer $\operatorname{sc} 5$ is a modification of pot 2 that was based on sequences obtained from clones of strains B, D, and E.

The clones obtained for the seven SCMV isolates used in this study contain a short poly(A) tract, the 3 -untranslated region of the viral genome, the sequence encoding the complete coat protein, and the $3^{\prime}$ half of the NIb gene. In all cases, there were nucleotide differences between the first two independent clones that were sequenced. In the majority of instances, the differences were in the third position of the codon and did not result in an amino acid change. The differences that resulted in an amino acid change are given in Table 2. These differences were confirmed by sequencing a third clone. In no cases was their evidence that the differences were due to errors during PCR amplification, hence, these differences reflect on the quasispecies nature of the populations. The complete sequences for all clones corresponding to approximately $2.0 \mathrm{~kb}$ of the 3 '-terminal region of the genomes of the four SCMV and three SrMV strains used in this study have been deposited with the GenBank data library under accession numbers U57354 (SCMV-A), U57355 (SCMV-B), U57356 (SCMV-D), U57357 (SCMV-E), U57358 (SrMV-SCH), U57359 (SrMV-SCI), and U57360 (SrMV-SCM) and are not presented here as a separate figure.

Partial sequences and comparisons of the NIb genes. The partial sequence of the $3^{\prime}$ half of the NIb gene was 276 amino acids in length for all seven isolates. The amino acid identity was from 98 to $100 \%$ within the SrMV group, and between 96 to $100 \%$ within the SCMV group with the exception that SCMVMDB was only 88 to $90 \%$ identical (Table 3 ). The amino acid identity between the two groups averaged about $76 \%$ (Table 3 ).

Sequences and comparisons of the coat protein genes. A multiple sequence alignment of the deduced coat protein and immediate upstream sequences of the seven isolates sequenced in this study, and the sequences of another seven members of the SCMV group for which the sequences are available from GenBank, is presented in Figure 2. The putative hydrolytic cleavage site, glutamine/serine or glutamine/alanine, between the replicase and the coat protein is indicated by the arrow. The amino acids surrounding these predicted cleavage sites conform to the consensus sequence recognized by the NIa proteinase responsible for cleavage of the coat protein from the viral polyprotein (15). The lengths of the SCMV and SrMV coat proteins varied from 305 to 329 residues. All strains of SrMV were 329 residues, SCMV-A was 304 residues, SCMV-B and -D were 309 residues, SCMV-E and -SC were 313 residues, and SCMV-MDB was 328 residues.
The amino acid identity was from 98 to $100 \%$ within the SrMV group, and between 96 to $100 \%$ within the SCMV group with the exception that SCMV-MDB was only 83 to $86 \%$ identical (Table $3)$. The amino acid identity between the two groups averaged about $75 \%$ (Table 3 ). The phylogenetic relationships of the conserved core (Fig. 2, residues 109 to 347) of the coat proteins (Fig. 3) among 14 members of the SCMV subgroup were examined using the Clustal W programs (21). In this analysis, SCMV-MDB groups with the rest of the SCMV strains. However, if the entire coat protein sequence was used, using the Clustal W parameter that allows alignment positions where any of the sequences have a gap to be ignored (21), SCMV-MDB did not group with the rest of the SCMV strains (Fig. 3).
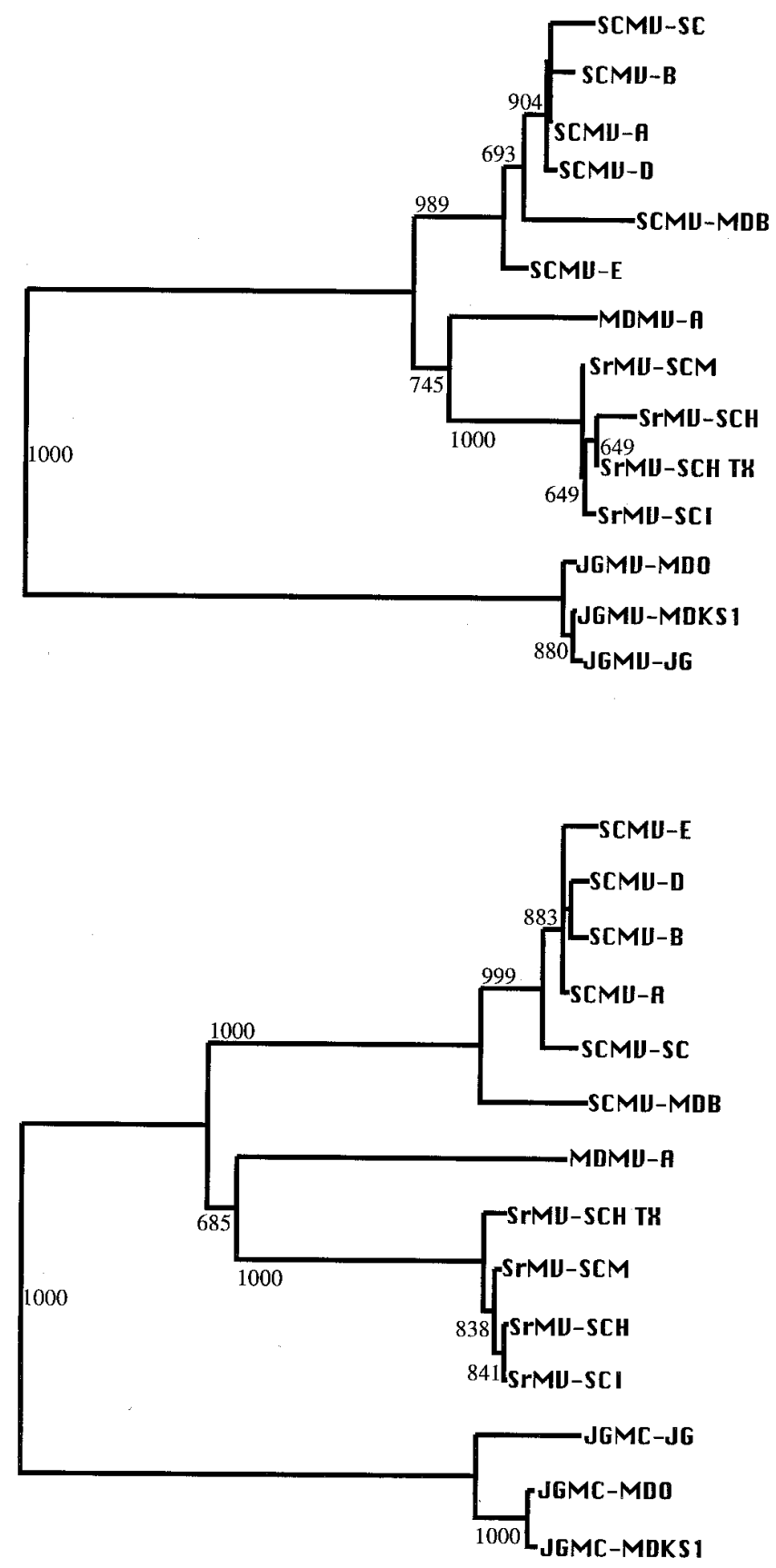

Fig. 3. Phylogenetic trees for the conserved core of the coat protein (residues 109 to 347 in Fig. 2) (top), and the entire coat protein (bottom). Trees were constructed by the neighbor-joining method with 1,000 bootstraps and the parameter that ignores alignment positions where any of the sequences have a gap (Clustal W). The number beside each node indicates the number of bootstrap replicates. 
One feature in the $\mathrm{N}$-terminal region of the coat proteins shared by all 14 members is the conserved DAG motif (Fig. 2), shown to be associated with aphid transmissibility (2). Another interesting feature in the $\mathrm{N}$-terminal region of the coat proteins of these new sequences is the short repeated peptide motifs, similar to those first observed for SCMV-SC by Frenkel et al. (5) and Xiao et al. (24). The sequence pattern GAQPPATGAAAQ (underlined in Fig. 2) was repeated nearly perfectly in the SCMV strains A, B, D, E, and SC. These five strains also contained a third partial repeat of PPA/TA/T. This was in contrast to the imperfect repeat motif of AGSGSGTGAGTGVTGGQ (underlined in Fig. 2) found in the
MDB strain of SCMV $(5,24)$. The three SrMV strains contained a third distinct pattern of DADAKKKADDEAA (underlined in Fig. 2) that was repeated exactly. A third nearly perfect repeat of this sequence was located between the two perfect repeats (Fig. 2). No repeated sequences were identified in the JGMV strains or in MDMV-A.

Sequences and comparisons of the $\mathbf{3}^{\prime}$-untranslated regions. The 3'-untranslated regions varied in length from 230 bases for the SCMV strains to 234 bases for the SrMV strains. The nucleotide sequence identity was from 97 to $100 \%$ within the SrMV group, and between 95 to $98 \%$ within the SCMV group with the

TABLE 4. Percent nucleotide sequence identity between the $3^{\prime}$-noncoding regions from strains of viruses in the sugarcane mosaic virus (SCMV) subgroup ${ }^{\mathrm{a}}$

\begin{tabular}{|c|c|c|c|c|c|c|c|c|c|c|c|c|c|}
\hline & $\begin{array}{l}\text { JGMV- } \\
\text { MDO }\end{array}$ & $\begin{array}{c}\text { JGMV- } \\
\text { JG }\end{array}$ & $\begin{array}{c}\text { SCMV- } \\
\text { A }\end{array}$ & $\begin{array}{c}\text { SCMV- } \\
\text { E }\end{array}$ & $\begin{array}{l}\text { SCMV- } \\
\text { D }\end{array}$ & $\begin{array}{l}\text { SCMV- } \\
\text { B }\end{array}$ & $\begin{array}{l}\text { SCMV- } \\
\text { SC }\end{array}$ & $\begin{array}{l}\text { SCMV- } \\
\text { MDB }\end{array}$ & $\begin{array}{l}\text { SrMV- } \\
\text { SCI }\end{array}$ & $\begin{array}{l}\text { SrMV- } \\
\text { SCM }\end{array}$ & $\begin{array}{c}\text { SrMV- } \\
\text { SCH (TX) }\end{array}$ & $\begin{array}{l}\text { SrMV- } \\
\text { SCH }\end{array}$ & $\begin{array}{c}\text { MDMV } \\
-A\end{array}$ \\
\hline JGMV-MDKS1 & 99 & 93 & 46 & 43 & 44 & 47 & 45 & 38 & 40 & 40 & 39 & 40 & 41 \\
\hline JGMV-MDO & & 92 & 45 & 43 & 44 & 47 & 45 & 38 & 39 & 39 & 35 & 39 & 41 \\
\hline SCMV-A & & & & 98 & 97 & 98 & 97 & 90 & 60 & 60 & 60 & 60 & 55 \\
\hline SCMV-E & & & & & 97 & 96 & 95 & 89 & 60 & 61 & 60 & 60 & 55 \\
\hline SCMV-D & & & & & & 98 & 95 & 90 & 60 & 60 & 60 & 60 & 57 \\
\hline SCMV-B & & & & & & & 95 & 89 & 60 & 60 & 60 & 60 & 55 \\
\hline SrMV-SCI & & & & & & & & & & 99 & 99 & 100 & 61 \\
\hline SrMV-SCM & & & & & & & & & & & 99 & 99 & 61 \\
\hline SrMV-SCH (TX) & & & & & & & & & & & & 97 & 60 \\
\hline SrMV-SCH & & & & & & & & & & & & & 61 \\
\hline
\end{tabular}

a The sources of sequence data and calculations of sequence identities were as in Table 3 .

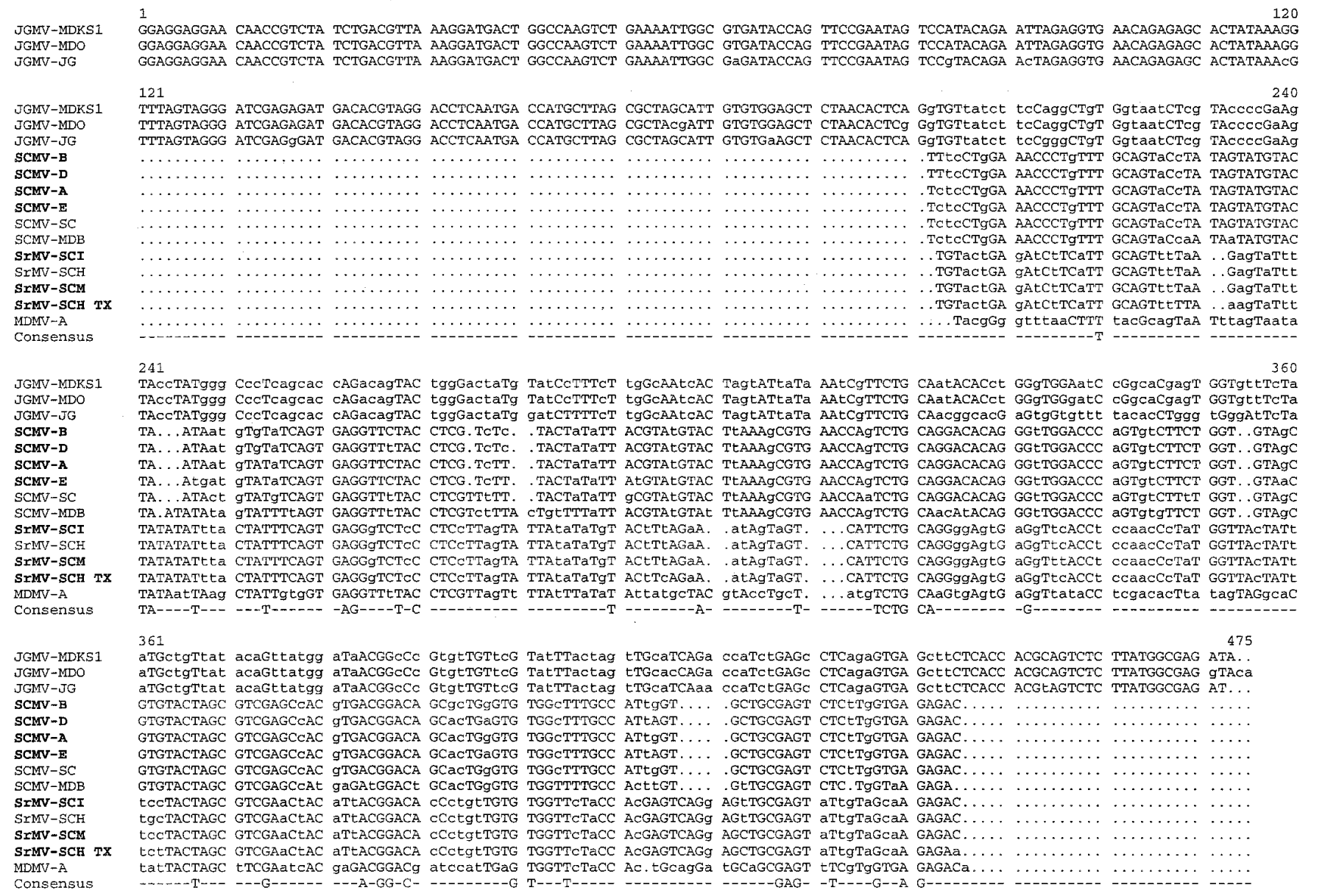

Fig. 4. Multiple alignment of nucleotide sequences in the $3^{\prime}$-untranslated region from 13 members in the sugarcane mosaic potyvirus subgroup. The alignment was generated using the PileUp and Pretty programs (University of Wisconsin Genetics Computer Group, Madison). Seven of these sequences have already been published; sequences of new strains are indicated in bold. Consensus nucleotides are given as upper case, and the Consensus line shows only nucleotides that are identical for all 14 members. 


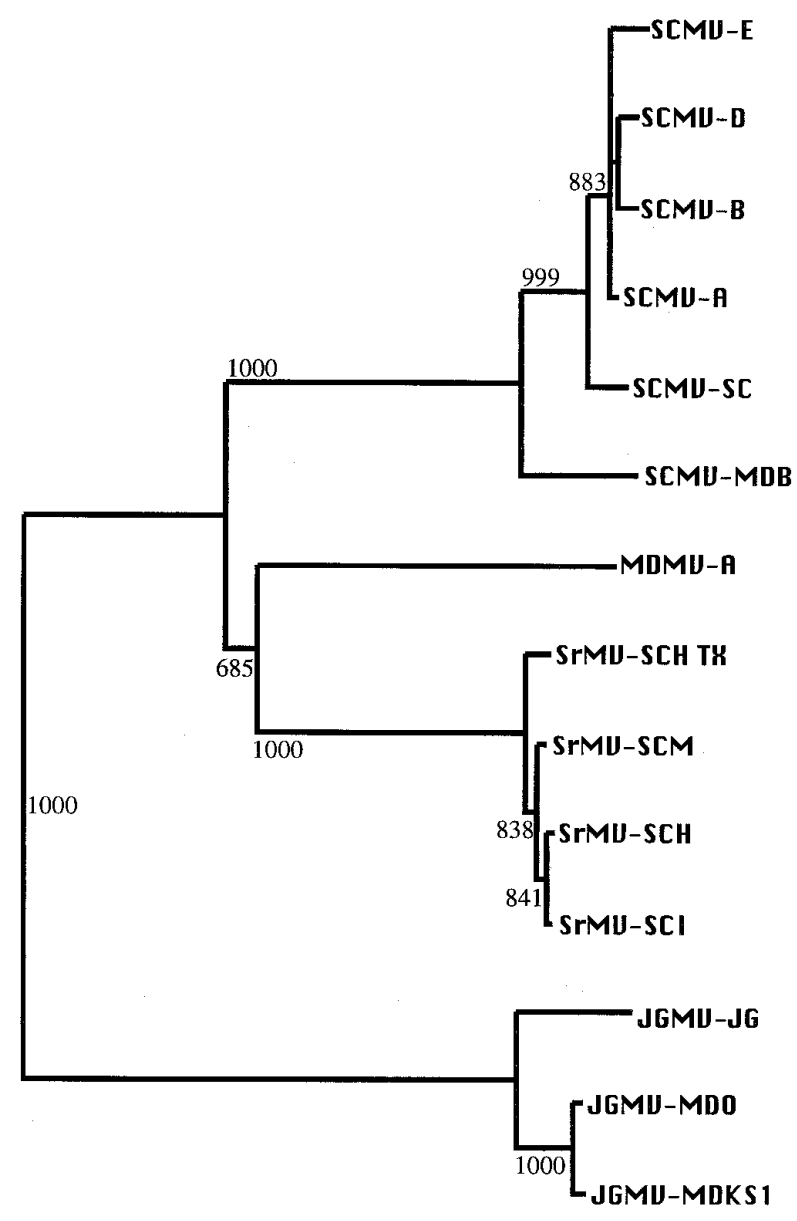

Fig. 5. Phylogenetic tree for the 3 '-untranslated region. The tree was constructed by the neighbor-joining method with 1,000 bootstraps and the parameter that ignores alignment positions where any of the sequences have a gap (Clustal W). The number beside each node indicates the number of bootstrap replicates. exception that SCMV-MDB was only 88 to $90 \%$ identical (Table $4)$. The nucleotide sequence identity between the two groups averaged about $60 \%$ (Table 4). A multiple sequence alignment of the $3^{\prime}$-untranslated nucleotide sequences of the seven isolates sequenced in this study, and the sequences of another seven members of the SCMV group for which the sequences are available from GenBank, is presented in Figure 4. The phylogenetic relationships were examined using the Clustal W programs (21) and are presented in Figure 5. SCMV-MDB did not group with the rest of the SCMV strains in this analysis.

Design of group-specific primers and RFLP analysis. Based on multiple nucleotide sequence alignments of our new sequences and published sequences for six other members of the SCMV subgroup, we were able to design group-specific primer pairs: primer pair SCMV F3 and R3 for SCMV strains, and primer pair SrMV F3 and R3 for SrMV strains (Table 1, Fig. 6). Our strategy utilized sequences in areas where there were "gaps" between the nucleotide sequences of the two groups, combined with regions where there were considerable nucleotide differences (Fig. 6).

The top panel of Figure 7 shows that RT-PCR with oligonucleotide pair SrMV F3 and R3 specifically prime amplification of the expected size product of $871 \mathrm{bp}$ using total RNA prepared from sorghum infected with either SrMV strains SCH, SCI, or $\mathrm{SCM}$, and that no product was amplified using total RNA prepared from sorghum infected with SCMV strains A, B, D, or E. The converse is shown in the bottom panel of Figure 7. RT-PCR products consistent with the expected ones of lengths 873, 885, 885 , and 897 bp for the SCMV strains A, B, D, and E, respectively, were obtained with the primer pair SCMV F3 and R3, and no product was amplified using total RNA prepared from sorghum infected with either SrMV strains SCH, SCI, or SCM. To differentiate the amplified DNAs from each of the viruses, we identified RFLPs that could distinguish the different strains in each subgroup (Figs. 7 and 8). The SrMV strains could be differentiated, for example, by digestion with $\mathrm{HgaI}$, and the SCMV strains could be differentiated, for example, by digestion with ApoI and $X b a \mathrm{I}$. There were also distinctive polymorphisms that were more complex, which could be resolved on polyacrylamide gels, that

\begin{tabular}{|c|c|c|c|c|c|c|c|c|c|}
\hline & 801 & & $\downarrow$ & & & & & & 900 \\
\hline GMV-MDKSI & . & & $\ldots$ & .tgcTaGAgG & ttGagcaTCA & AtCAGGcaAT & GaAgAtGCtG & GAAgACAGaa & GagTGCggCA \\
\hline MDO & $G$ & & & . tgcTaGAgG & ttGagcaTCA & AtCAGGcaAT & GaAgAtGCtG & GAAgACAGaa & aagTGCggCA \\
\hline$J G$ & & & & . tgGTgGATG & tAGaacatcA & AT & GCtG & ACAGaa & GagTGCAACA \\
\hline$M V-B$ & $\mathrm{AC}$ & $\mathrm{GGTTT}$ & $\mathrm{IGC} \mathrm{TG}$ & ACAGTCGATG & CTCA & $g \mathrm{~T}$ & & & $\mathrm{CCACC}$ \\
\hline$-D$ & $\mathrm{AC}$ & $\frac{T T}{T T}$ & AaGC TGG & CGATG & $\mathrm{TCA}$ & $\mathrm{GgT}$ & $\mathrm{GCCG}$ & GAACtCAGCC & GCCaGCAACC \\
\hline SCMV-E & $A A C$ & TTT & TtCACCAaGC TGGA. & $\bar{A} C A G T C G A T G$ & TCA & $\mathrm{ggT}$ & $\operatorname{CcG}$ & ECAGCC & GCCaGCcACt \\
\hline$-A$ & $A C$ & & $\mathrm{TtCl}$ & & $C A$ & & CG & CC & aGCCACt \\
\hline SC & & & TCC & & & & & & GCCACt \\
\hline $\mathrm{MDB}$ & at & & $\overline{\mathrm{TCCA}}$ & $\bar{A} \mathrm{C}$ & & & & & $\mathrm{AACA}$ \\
\hline SCI & $\mathrm{Ea}$ & & $\mathrm{gCC}$ & $\mathrm{AC}$ & ac & & acc & $\mathrm{Cg}$ & $A \mathrm{AC}$ \\
\hline SMV-SCM & Aacta & Igc & $\mathrm{IC}$ aGC & $\mathrm{ACA}$ & Cagc & $A G \overline{A \bar{a}}$ & $\overline{\mathrm{GCA} A}$ & GCg & TGCAgCA \\
\hline$r M V-S C H \quad \mathrm{TX}$ & gAacta & attGACGTgC & AGGC aGGI & ACAGTaGATG & CAGGaGCaac & CaCAGCAGÃa & $\mathrm{GCac}$ & $\overline{\mathrm{aAgCACA}} \mathrm{GCg}$ & tgaTGCAgCA \\
\hline $\mathrm{rMV}-\mathrm{SCH}$ & Eta & att & GC aGGAGGCGGT & ACAGTaGATG & CAGGaGCaac & CaCAGCAGAa & GCAACaGCac & aAgCACAGCg & tgaTGCAgCA \\
\hline & & & GGC & & & & & $\ldots$ & ggTGaAAat \\
\hline
\end{tabular}

JGMV-MDKSI JGMV-MDO JGMV-JG SCMV - B SCMN -D SCMV-E SCMV $-\mathrm{A}$ SCMV-SC SCMV-MDB SrMV-SCI SrMV-SCM SIMV-SCH TX $\mathrm{SrMV}-\mathrm{SCH}$ MDMV-A
1701

gAacCaCATG TTtGGaCTCG ACGGGAATGT tgGaGAGAgC tctgAGAATA CAGAGCGgCA CACAGCTGca GATGTCtcaC GgAATqTCCA tTCgtacCgt gAacCaCATG TTLGGaCTCG ACGGGAATGT tGGaGAGAgC tctGAGAATA CAGAGCGgCA CACAGCTGCa GATGTC gAaCCaCATG TTtGGaCTCG ACGGGAATGT tGGaGAGAgC tctGAGAACA CAGAGCGgCA CACAGCTGCa GATGTCtCaC GgAATgTtCA tTCgtaCCgt CACACGatTG TTCGGTCTGG ACGGaAATGT CGGCGAGACC CAGGAGAATA CAGAGaGACA CACAGCTGGC GATGTCAGTC GtAACATGCA CTCTCTGtTG CACACGatTG TTCGGTCTGG ACGGaAATGT CGGCGAGACC CAGGAGAATA CAGAGaGACA CACACGatTG TTCGGTCTGG ACGGaAATGT CGgCGAGACC CAGGAGAATA CAGAGagACA CACAGCTGGC GATGTCAGTC GCAACATGCA CTCTCTGtTG CACACGatTG TTCGgTCTGG ACGGaAATGT CGGCGAGACC CAGGAGAATA CAGAGaGACA CACAGCTGGC GATGTCAGTC GCAACATGCA CTCTCTGtTG CACACGatTG TTCGGTCTGG ACGGaAATGT CGGCGAGACC CAGGAGAATA CAGAGaGACA CACAGCTGGC GATGTCAGTC GCAACATGCA CTCTCTGtTG

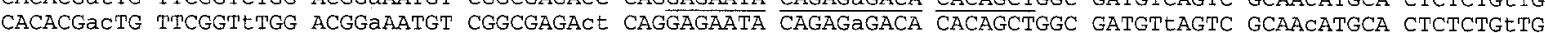
CACgCGCATG TTtGGCtTGG AtGGGAATGT CGGtGAGAgt CAGGAGAATA CAGAaCGtCA CACAGCTGGC GATGTgAGTC GCAATATGCA CTCCCTECT CACgCGCATG TTtGGCtTGG AtGGGAATGT CGGtGAGAgt CAGGAGAATA CAGAaCGtCA CACAGCTGGt GATGTgAGTC GCAATATGCA CTCCCTtCTt CACgCGCATG TTtGGctTGG AtGGGAATGT CGGtGAGAgt CAGGAGAATA CAGAaCGtCA CACAGCTGGC GATGagAGTC GCAATATGCA CTCCCTtCT CACgCGCATG aadGGCtTGG AtGGGAATGT CGGtGAGAgt CAGGAGAATA CAGAaCGtCA CACAGCTGGC GATGagAGTC GCAATATGCA CTCCCTtCTC

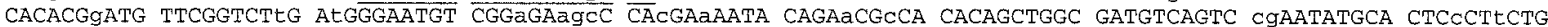

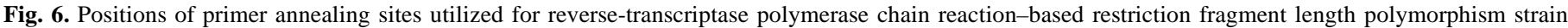

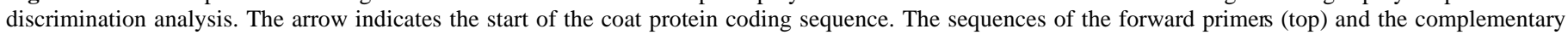

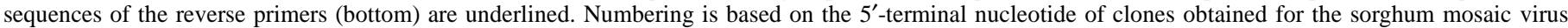
strains. The $3^{\prime}$ ends of the sequences presented in the bottom half are just upstream of the coat protein stop codons. 
could be generated with TaqI, Sau3AI, and HinfI. These restriction enzymes digest the amplification products at three or four sites (Fig. 8)

An example of the identification of unknown field isolates is given in the bottom panel of Figure 8. The five unknowns were first determined to be strains of SCMV as only the SCMV-specific primer pair primed the amplification of RT-PCR products (data not shown). Digestion of the RT-PCR products with TaqI revealed that isolates 2 and 5 were SCMV strain A, and that isolate 1 was SCMV strain B (Fig. 8). The TaqI RFLP could not distinguish whether isolates 3 and 4 were SCMV strain D or E. Further analysis with HinfI and $\mathrm{XbaI}$ digestions showed that both isolates 3 and 4 were SCMV strain E (data not shown).

\section{DISCUSSION}

Until recently, it was well recognized that the taxonomy of the potyviruses was in a "very unsatisfactory state" (23). However, the continuous accumulation and analysis of potyvirus genomic sequence data appears to have overcome these problems. Shukla and Ward (17) and Ward et al. (23) have demonstrated that coat protein gene sequence data can be used to provide a hierarchical classification of potyviruses. They found that pairwise coat protein amino acid sequence comparisons among 17 strains of eight distinct potyviruses showed a bimodal distribution. Distinct viruses of the group exhibited sequence identities from 38 to $71 \%$, whereas strains of the same virus exhibited sequence identities from 90 to $99 \%$. Additional sequence data (12) have identified a

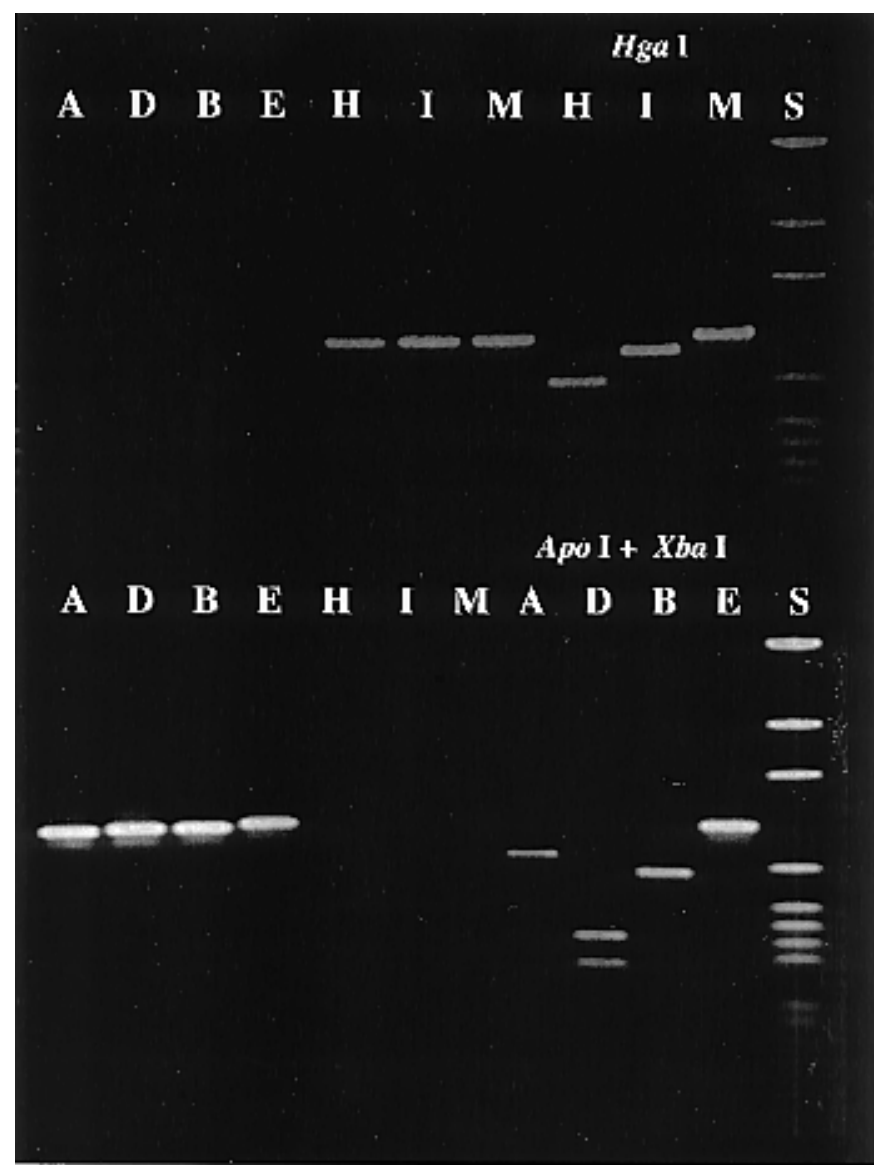

Fig. 7. Restriction fragment length polymorphism of reverse-transcriptase polymerase chain reaction products from strains of sugarcane mosaic potyvirus (SCMV) and sorghum mosaic virus (SrMV). Amplification products using SrMV-specific primers (Table 1) and discrimination between strains $\mathrm{H}$, I, and M, with $\mathrm{HgaI}$ digests (top). Amplification products using SCMV-specific primers (Table 1) and discrimination between strains $\mathrm{A}, \mathrm{B}, \mathrm{D}$, and $\mathrm{E}$, with ApoI and $\mathrm{XbaI}$ digests (bottom). S, molecular weight markers from top to bottom: $2,645,1,605,1,198,676,517,460,396$, and $350 \mathrm{bp}$. third cluster in the 75 to $89 \%$ range. Shukla and Ward (17) have proposed that viruses that fall into this group should be considered distinct species rather than strains of the same virus.

We applied the criteria of Shukla and Ward (17) to our comparative sequence analysis of the seven viruses sequenced in this study and six other members of the SCMV subgroup for which sequence data were available in GenBank (Tables 3 and 4). Based on their criteria, our comparative sequence analysis confirms prior biochemical analysis $(8,11,16)$ that identified at least four distinct groups of SCMV, but suggests that there are five distinct groups. When compared with SCMV strains A, B, D, E, and SC, the identities for SCMV-MDB ranged from only 83 to $86 \%$ in the coat protein, and from 88 to $90 \%$ in the NIb gene and the 3 -untranslated region. As proposed by Shukla and Ward (Fig. 3 in literature citation 12), this is below the cutoff point for strains of the same virus and, hence, SCMV-MDB would be considered a distinct species rather than a strain of SCMV. Additional data that would argue that SCMV-MDB be considered a distinct virus, rather than a strain of SCMV, would be the lack of relatedness between the repeated peptide motifs found in the N-terminal region of the SCMV-MDB coat protein and those found in the other SCMV strains (Fig. 2). Furthermore, SCMV-MDB does not infect sugarcane. It will be of interest to determine by sequence analysis if the Australian strains of SCMV that do not infect sugarcane fall into this fifth group of the SCMV complex.

With this work, we provide the first biochemical method that can distinguish strains of SCMV and SrMV. Prior to this, the only

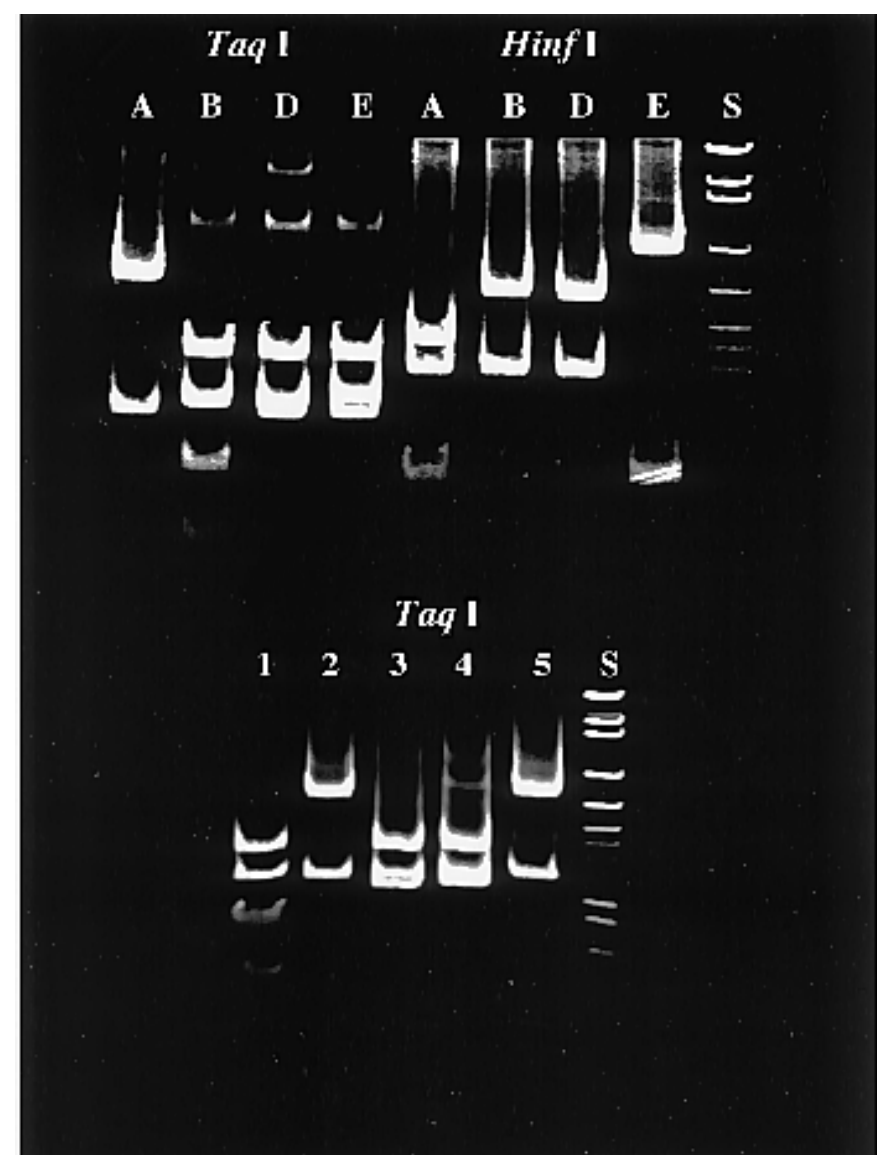

Fig. 8. Restriction fragment length polymorphism (RFLPs) of reverse-transcriptase polymerase chain reaction products from strains of sugarcane mosaic potyvirus (SCMV) and strain determination of unknown field isolates. RFLPs of amplification products using known SCMV strains with SCMVspecific primers (Table 1) and discrimination between strains A, B, D, and E, with TaqI and HinfI digests (top). Strain determination of unknown field isolates of strains of SCMV (bottom). S, molecular weight markers from top to bottom: $2,645,1,605,1,198,676,517,460,396$, and $350 \mathrm{bp}$. 
method available to differentiate strains was based on symptom variation on a set of differential hosts developed by Abbott and Tippett (1). Smith and van de Velde (19) have developed a RTPCR-based detection system for strains of SCMV, but their strategy was not designed to allow for strain discrimination using RFLP analysis. Our method uses two sets of group-specific oligonucleotides that prime amplification of a region of the coat protein gene that contains RFLPs. We have shown that the SCMV primers F3 and R3 (Table 1) are specific to the SCMV strains A, $\mathrm{B}, \mathrm{D}$, and $\mathrm{E}$ (Fig. 7). Based on sequence comparisons, these primers would result in amplification products from tissue infected with the SC strain of SCMV, but not from tissue infected with MDMV-A, MDMV-B, or strains of JGMV. Again, based on sequence comparisons, it is predicted that the SrMV-specific primers would not result in PCR products from tissue infected with MDMV-A, MDMV-B, or strains of JGMV, and we have demonstrated that they will not result in PCR products from tissue infected with strains of SCMV. This method should facilitate rapid identification and discrimination of strains from unknown field isolates (Fig. 8).

\section{ACKNOWLEDGMENTS}

This work was supported by grants from the American Sugar Cane League, the International Consortium for Sugarcane Biotechnology, and the Rio Grande Valley Sugar Growers, Inc. We thank M. Grisham, M. Irey, and P. Rott for providing virus isolates, and J. Irvine for helpful discussions.

\section{LITERATURE CITED}

1. Abbot, E. V., and Tippett, R. L. 1966. Strains of sugarcane mosaic virus. U.S. Dep. Agric. Res. Serv. Tech. Bull. 1340:1-25.

2. Atreya, P. L., Atreya, C. D., and Pirone, T. P. 1991. Amino acid substitutions in the coat protein result in loss of insect transmissibility of a plant virus. Proc. Natl. Acad. Sci. U.S.A. 88:7887-7891.

3. Colinet, D., and Kummert, J. 1993. Identification of a sweet potato feathery mottle virus isolate from China (SPFMV-CH) by the polymerase chain reaction with degenerate primers. J. Virol. Methods 45: 149-159.

4. Devereux, J., Haeberli, P., and Smithies, O. 1984. A comprehensive set of sequence analysis programs for the VAX. Nucleic Acids Res. 12:387-395.

5. Frenkel, M. J., Jilka, J. M., McKern, N. M., Strike, P. M., Clark, J. J. M., Shukla, D. D., and Ward, C. W. 1991. Unexpected sequence diversity in the amino-terminal ends of the coat proteins of strains of sugarcane mosaic virus. J. Gen. Virol. 72:237-242.

6. Grisham, M. P. 1994. Strains of sorghum mosaic virus causing sugarcane mosaic in Louisiana. Plant Dis. 78:729-732.

7. Koike, H., and Gillaspie, A. G. 1989. Mosaic. Pages 301-322 in: Diseases of Sugarcane-Major Diseases. C. Ricaud, B. T. Eagan, and A. G. Gillaspie, eds. Science Publishers, Amsterdam.

8. Lesemann, D. E., Shukla, D. D., Tosic, M., and Huth, W. 1992. Differ- entiation of the four viruses of the sugarcane mosaic virus subgroup based on cytopathology. Arch. Virol. Suppl. 5:353-361.

9. Louie, R., and Knoke, J. K. 1975. Strains of maize dwarf mosaic virus. Plant Dis. Rep. 59:518-522.

10. Matthews, R. E. F. 1982. Classification and nomenclature of viruses. Fourth report of the International Committee on Classification of Viruses. Intervirology 17:1-99.

11. McKern, N. M., Shukla, D. D., Toler, R. W., Jensen, S. G., Tosic, M., Ford, R. E., Leon, O., and Ward, C. W. 1991. Confirmation that the sugarcane mosaic virus subgroup consists of four distinct potyviruses by using peptide profiles of coat proteins. Phytopathology 81:1025-1029.

12. Mink, G. I., Vetten, H. J., Ward, C. W., Berger, P. H., Morales, F. J., Myers, J. M., Silbernagel, M. J., and Barnett, O. W. 1994. Taxonomy and classification of legume-infecting potyviruses. A proposal from the Potyviridae Study Group of the Plant Virus Subcommittee of the ICTV. Arch. Virol. 139:231-235.

13. Pirone, T. P. 1972. Sugarcane mosaic virus. No. 88 in: Descriptions of Plant Viruses. Commonw. Mycol. Inst./Assoc. Appl. Biol., Kew, Surrey, England.

14. Sambrook, J., Fritsch, E. F., and Maniatis, T. 1989. Molecular Cloning: A Laboratory Manual. Cold Spring Harbor Laboratory Press, Cold Spring Harbor, NY.

15. Shukla, D. D., Frenkel, M. J., and Ward, C. W. 1991. Structure and function of the potyvirus genome with special reference to the coat protein coding region. Can. J. Plant Pathol. 13:178-191.

16. Shukla, D. D., Tosic, M., Jilka, J., Ford, R. E., Toler, R. W., and Langham, M. A. C. 1989. Taxonomy of potyviruses infecting maize, sorghum, and sugarcane in Australia and the United States as determined by reactivities of polyclonal antibodies directed towards virus-specific N-termini of coat proteins. Phytopathology 79:223-229.

17. Shukla, D. D., and Ward, C. W. 1988. Amino acid sequence homology of coat proteins as a basis for identification and classification of the potyvirus group. J. Gen. Virol. 69:2703-2710.

18. Shukla, D. D., Ward, C. W., and Brunt, A. A. 1994. The sugarcane mosaic virus subgroup. Pages 360-371 in: The Potyviridae. CAB International, Wallingford, United Kingdom.

19. Smith, G. R., and van de Velde, R. 1994. Detection of sugarcane mosaic virus and Fiji disease virus in diseased sugarcane using the polymerase chain reaction. Plant Dis. 78:557-561.

20. Teakle, D. S., Shukla, D. D., and Ford R. E. 1989. Sugarcane mosaic virus. No. 342 (no. 88 revised) in: Descriptions of Plant Viruses. Commonw. Mycol. Inst./Assoc. Appl. Biol., Kew, Surrey, England.

21. Thompson, J. D., Higgins, D. G., and Gibson, T. J. 1994. CLUSTAL W: Improving the sensitivity of progressive multiple sequence alignment through sequence weighting, position specific gap penalties and weight matrix choice. Nucleic Acids Res. 22:4673-4680.

22. Tosic, M., Ford, R. E., Moline, H. E., and Mayhew, D. E. 1974. Comparison of techniques for purification of maize dwarf and sugarcane mosaic viruses. Phytopathology 64:439-442.

23. Ward, C. W., McKern, N. M., Frenkel, M. J., and Shukla, D. D. 1992. Sequence data as the major criterion for potyvirus classification. Arch. Virol. Suppl. 5:283-297.

24. Xiao, X. W., Frenkel, M. J., Teakle, D. S., Ward, C. W., and Shukla, D. D. 1993. Sequence diversity in the surface-exposed amino-terminal region of the coat proteins of seven strains of sugarcane mosaic virus correlates with their host range. Arch. Virol. 132:399-408. 